\title{
Supplementation of Either Conjugated Linoleic Acid or $\gamma$-linolenic Acid with or without Carnitine to Pig Diet Affect Flavor of Pork and Neutrophil Phagocytosis
}

\author{
Jun Yeob Lee ${ }^{1}$, Keun Hwan $\mathrm{Cha}^{2}$, Byong Jo Chae ${ }^{1}$ and Sang Jip Ohh ${ }^{1 *}$ \\ ${ }^{1}$ College of Animal Life Sciences, Kangwon National University, Chuncheon, Korea, \\ ${ }^{2}$ Korea Feed Ingredients Association, Seoul, Korea
}

\begin{abstract}
In this study, four different oils containing either CLA, GLA, GLA+Carnitine or corn oil (control) were supplemented to finishing pigs (average $70.8 \mathrm{~kg}$ initial BW) diet for $28 \mathrm{~d}$ of feeding period. To evaluate the values of the dietary fatty acids, especially in view of sensory and nutritional characteristics of pork; pig performances, carcass characteristics, serum cholesterol, neutrophil phagocytosis, TBARS, electronic nose flavor and fatty acids profile of pork were measured. There were no differences in daily gain and nutrients digestion among treatments, but daily feed intake of CLA enriched diet was lower $(\mathrm{P}<0.05)$ than that of other diets. There were no differences in backfat thickness, dressing percentage and carcass grade among pigs fed diets supplemented with different oils. Serum total cholesterol showed a tendency to be lowered in pigs fed GLA enriched diet. TBARS values during storage of pork were higher in belly from pigs fed control diet whereas the values of belly from pigs fed GLA+Carnitine diet were lower than others. However, difference in TBARS was not remarkable in adipose tissue and 4 weeks extended storage regardless of pork parts. Proportion of saturated fatty acids such as $\mathrm{C} 16: 0$ and $\mathrm{C} 18: 0$ were higher $(\mathrm{P}<0.05)$ in pork loin and thin skirt from pigs fed CLA enriched diet compared to those from other diets. There were no differences in fatty acids profiles of belly and adipose tissue. CLA accumulation in pork was increased by the dietary CLA supplementation and this could be also confirmed by a slight de novo synthesis of CLA in pork from pigs fed CLA free diets. GLA was selectively accumulated to pork adipose tissue and loin from pigs fed GLA enriched diets. There was no accumulation of GLA when GLA was not supplemented, indicating no de novo synthesis of GLA. Phagocytic activity was the highest $(\mathrm{p}<0.05)$ in neutrophil of pigs fed GLA+Carnitine supplemented diet, then, followed by pigs fed GLA supplemented diet. There was no difference in phagocytosis between control and CLA treatment although the phagocytosis was numerically lowest in pig fed CLA enriched diet. There were distinct differences in electronic nose flavor pattern among treatments regardless of the parts. This study showed that dietary supplementation of functional fatty acids like CLA or GLA was able to result in characteristic differences in feed intake, TBARS, fatty acids profile and flavor of pork, serum cholesterol regulation and neutrophil phagocytosis.
\end{abstract}

(Key words : CLA, GLA, Carnitine, Pork quality, Fatty acids profile, Flavor, Phagocytosis)

\section{INTRODUCTION}

Pork quality became a decisive factor for consumer upon shop selection of pork parts and further, its characterized brand. The quality of pork has been typically characterized by backfat thickness and color of meat. However, those quality items have primarily stood for the perspectives of packer and producer. Today, consumers are beginning to pay more attention to sensory as well as nutritional qualities of pork. These sensory and nutritional qualities have been, by far, represented as functional fatty acids and cholesterol contents, fatty acids profile, physico- chemical properties of meat and adipose tissue, and sensory characteristics of pork.
Once categorized, most of these qualities are associated with fat characteristics and fatty acids profile of the pork.

Therefore, there have been numerous diet manipulation approaches to induce changes in fat properties. Among those, dietary manipulation of fat and fatty acids has been widely employed to improve pork quality especially in terms of nutritional, sensory and shelf life characteristics (Ellis and Mckeith, 2010). Since fat characteristics and quality of pork are closely related to the fatty acid composition of the intra pork fat depots (Owen et al., 2001; Moremo et al., 2008), dietary manipulation has also focused on the technology to transport intended fatty acids to the either adipose or intra muscular fat depots.

* Corresponding author : Sang Jip Ohh, College of Animal Life Sciences, Kangwon National University, 1 Kangwondaehak-gil, Chuncheon-si, Gangwon-do, 200-701, Korea, Tel: +82-33-250-8631, E-mail: sjohh@kangwon.ac.kr 
To be specific on modulation of pork fat and fatty acids, researchers (Bee, 2001; Dugan et al., 2004) have paid special attention to several functional fatty acids such as conjugated linoleic acid(CLA) and gamma linolenic acid(GLA). The CLA and GLA were supplemented to impart them into pork and to anticipate health nutritional effects from the fatty acids. It is already known that the dietary fatty acids can be absorbed intact and deposited into pork (Dugan et al., 1997; Takada and Saitoh, 1998). If pig's diet was not supplemented with fatty acids, there occur de novo syntheses of mostly saturated or mono-unsaturated fatty acids. Therefore, those fatty acids become prevalent in most of pork. However, the polyunsaturated fatty acids deposition only occurs once the fatty acids or its pre-elongated fatty acids are supplemented.

Fatty acids profile in pork also has known to affect the sensory characteristics of pork. Degree of the soft fat problem is known to be highly proportional to the amount of unsaturated fatty acids in the pork. Occurrence of the soft fat problem was also higher when there were limited amount of de novo fatty acid synthesis in pigs while most of fatty acids in the carcass were derived from the diet (Eggert et al., 2001). Proportion of polyunsaturated fatty acids (PUFA) was generally higher in leaner pigs having thinner backfat. Among PUFAs, linoleic acid $(\mathrm{C} 18: 2)$ has been proposed to be highly responsible for the soft fat problem since the proportion of this fatty acid is relatively high in both popular feed ingredient like corn and vegetable oils (Teye et al., 2006).

Recently, modification of pork in terms of health nutritional value is receiving consumer's attention. Pork with less fat and functional nutrients-, especially $n-3$ fatty acids (Riediger et al., 2009), CLA- or GLA- fortified pork have been introduced in this perspective. In addition, carnitine was also supplemented individually or in combination with other fatty acids. Feeding $n-6$ or $n-3$ PUFA increased the content of these fatty acids in pork liver, spleen, lung and plasma (Sioutis et al., 2008; Dodson et al., 2010; Selvaraj and Cherian, 2004). Since CLA are stable and would not be easily saturated before absorption, CLA has been considered as an efficient fatty acid to be transported into pork.

Thereafter, beneficial effects of CLA supplementation to swine diet has been widely acknowledged especially in terms of improved feed efficiency as well as remarkable reduction in backfat thickness (Dugan et al., 1997; 1999; 2004). However, those benefits could (Martin et al., 2003) not be directly reflected to the sensory and health-nutritional quality of pork. By far, a few studies have been available for the effect of dietary CLA on organoleptic pork quality and intra pork fortification of CLA. Dietary CLA supplementation was reported to increase pork belly hardness, which is a preferred sensory quality by consumer. However, there are other fat associated pork qualities such as flavor and rancidity, which should be compounded or compromised with fat hardness to establish overall sensory quality. Furthermore, CLA in the pork was anticipated as a source of CLA for human (Reche et al., 2002). However, little has been known about the fatty acids profiles of pork (Joo et al., 2002) and especially the degree of intra pork CLA deposition after CLA feeding.

Compare to CLA, GLA was recently emerged as a functional fatty acid which is worth to be supplemented to pig diet for manipulating pork quality. With the increasing knowledge for the health benefit of GLA, dietary GLA supplementation to impart intra pork GLA has drawn the recent attention. GLA was reported to prevent fatty acid oxidation (Menendez et al., 2005) although GLA itself is one of PUFA which could accelerate lipid peroxidation (Lykkesfeldt and Svendsen, 2007). In addition, immunological benefit of dietary GLA was witnessed (Yaqoop and Hemat, 2004) although any type of innate immune response due to GLA has not confirmed in pig yet. Therefore it is worth to evaluatethe effect of supplemental GLA on pig responses as well as on pork quality (Palombo et al., 2000).

However, GLA depot to the tissue has been relatively poor compare to other PUFA. Therefore, it is needed to find supplemental measure to synergistically improve the physiological function and intra pork deposition of GLA. Since carnitine has been known as a transporter of fatty acids into mitochondria, where the fatty acids are oxidized(Hemat, 2004), it is hypothesized from carnitine to anticipate possible synergism to GLA by increasing its mobilization. By far in our knowledge, GLA supplementation along with carnitine has not been tested. Dietary carnitine alone supplementation often resulted benefits on reducing backfat but increasing the proportion of lean (Owen et al., 2001). Carnitine was also known to stabilize blood $\mathrm{pH}$ change in pig therefore has been supplemented to ameliorate the impact of a stress like transportation (Bertol et al., 2005 James, 2009). In this regard, we hypothesized this role of carnitine might affect sensory quality of pork. Since carnitine was known to stimulate the transfer of fatty acids and acetyl groups via mitochondria matrix (Hoppel, 2003; Xi et al., 2008), we further hypothesized 
there would be an increased cellular mobilization of the supplemented GLA and other long chain fatty acids.

Therefore, this study was aimed to comparatively evaluate the sensory characteristics, fatty acids profiles and CLA or GLA accumulation in pork from pigs fed diets supplemented with either CLA, GLA or GLA+carnitine and corn oil as control. In addition, neutrophil phagocytosis and pig performance were also measured upon the same dietary regimen.

\section{MATERIALS AND METHODS}

\section{Animals and diets}

Totally, 48 crossbred finishing pigs (25 barrows and 23 gilts, Yorkshire $\times$ Landrace $\times$ Duroc) with initial BW of $70.8 \pm$ $7.8 \mathrm{~kg}$ were randomly assigned for $28 \mathrm{~d}$ feeding study to one of 4 dietary treatments with 2 pens per treatment by allotting the equal numbers of barrows and gilts in a pen with one exception. All pigs were housed in concrete-floor pens in an environmentally controlled facility. Basal diet was formulated to meet or exceed the NRC (1998) nutrients requirements (Table 1). All diets were supplemented with $1 \%$ level of one of different oil sources and $8,000 \mathrm{mg}$ of atocopherol as an antioxidant. Control and 3 treatments were named according to the enriched fatty acid in the respective supplemental oils such as Control (corn oil), CLA, GLA and GLA + Carnitine. The supplemented oil sources and carnitine source used for the treatments are prepared as follow; commercial $100 \%$ corn oil for control, CLA rich oil containing 58.6\% CLA (Samwoo Oil Co., Korea), evening primrose oil containing 9.2\% GLA (Samkwang Chemical Co., Korea) and commercial carnitine supplement (Easybio Co., Korea). For carnitine treatment, $50 \mathrm{ppm}$ carnitine was supplemented in combination with GLA. Each pen was equipped with the self-feeder and a nipple waterer to allow the pig ad libitum access to feed and water during the entire experimental period. Body weight and feed intake were measured in the beginning and termination of experiment to determine ADG, ADFI, and FCR.

\section{Apparent nutrients digestibility}

After termination of feeding trial, nutrients digestibility trial was conducted with experimental diets containing $0.2 \%$ $(\mathrm{w} / \mathrm{w})$ chromic oxide as a digestibility marker. Each pig was used as an experimental unit. The fecal sample collection was started at $24 \mathrm{~h}$ after initial feeding and terminated at 2 $\mathrm{d}$ since the initial feeding. Samples of diets and collected feces were analyzed for DM, CP, crude fat and crude ash according to the methods of AOAC (1985). Energy was analyzed using bomb calorimeter(1260, Parr Co., USA). Chromic oxide content in feed and feces was analyzed according to the procedure described by Fenton and Fenton (1979).

\section{Carcass evaluation}

After the end of the feeding trial, 3 pigs with similar body weight per treatment were slaughtered by electrical stunning, then exsanguinated, dressed and longitudinally divided into 2 halves. Dressing percentage was calculated from carcass weight and live body weight and backfat thickness was measured at the first rib, $10^{\text {th }}$ rib, ands the last rib. Carcass grade was evaluated by registered expert at the slaughter referring with Korea pork qualification standard.

\section{Fatty acid and TBARS analysis}

Loin, belly, skirt and adipose tissue sample for fatty acid and lipid oxidation analyses were removed from the mid-portion between $6^{\text {th }}$ and $8^{\text {th }}$ rib of the carcass. Lipids were extracted from each meat sample using chloroform: methanol (2:1) as described by Folch et al. (1957). The fatty acid methyl esters (FAME) of diets and lipids for fatty acid analysis were prepared using the method described by Sukhija and Palmquist (1988).

The fatty acid composition of the FAME was determined by capillary GC on a SP-2560, $100 \mathrm{~m} \times 0.25 \mathrm{~mm} \times 0.20 \mu \mathrm{m}$ capillary column (Supelco Co., Bellefonte, PA, USA) installed on a Hewlett Packard 5890 gas chromatography equipped with a flame ionization detector and splitless injector. The initial oven temperature was $140^{\circ} \mathrm{C}$, held for $5 \mathrm{~min}$, subsequently increased to $240^{\circ} \mathrm{C}$ at a rate of $3^{\circ} \mathrm{C}$ per min, and then held for $15 \mathrm{~min}$. Helium was used as the carrier gas at a flow rate of $1.1 \mathrm{~mL}$ per min. Both injector and the detector were set at $250^{\circ} \mathrm{C}$. Fatty acids were identified by comparing their retention times with the FAME standards.

The CLA composition of the FAME was determined by capillary GC on a SP-2340, $60 \mathrm{~m} \times 0.32 \mathrm{~mm} \times 0.20 \mu \mathrm{m}$ capillary column (Supelco Co.) installed on a Hewlett Packard 5890 gas chromatography equipped a flame ionization detector and 
splitless injector. The initial oven temperature was $70^{\circ} \mathrm{C}$, held for $4 \mathrm{~min}$, subsequently increased to $175^{\circ} \mathrm{C}$ at a rate of 13 ${ }^{\circ} \mathrm{C}$ per min, and then held for $27 \mathrm{~min}$ and then, increased to $215^{\circ} \mathrm{C}$ at a rate of $4^{\circ} \mathrm{C}$ per min. Helium was used as the carrier gas at a flow rate of $0.6 \mathrm{~mL}$ per min. Both injector and the detector were set at $210^{\circ} \mathrm{C}$ and $230^{\circ} \mathrm{C}$, respectively. Conjugated linoleic acids were identified by comparing their retention times with the commercial CLA isomer methyl ester standards.

Lipid oxidation was determined by thiobarbituric acid reactive substance (TBARS) method of Witte et al. (1970). In brief, the ground meat samples $(0.4 \mathrm{~g}$ of belly or $0.1 \mathrm{~g}$ of adipose tissue) was weighed and transferred into test tubes, followed by addition of 3 drops of freshly made antioxidant solution, $3 \mathrm{~mL}$ of 2-thiobarbituric acid solution and $17 \mathrm{~mL}$ of trichloroacetic acid-HCl solution. After vortexing for $3 \mathrm{sec}$, test tubes were incubated for $30 \mathrm{~min}$ in a water bath at 100 ${ }^{\circ} \mathrm{C}$. After termination of reaction, reactants were transferred into new tubes, followed by addition of $2 \mathrm{~mL}$ of chloroform and then centrifuged for $15 \mathrm{~min}$ at $3,000 \mathrm{rpm}$. The supernatant was measured for absorbance at $532 \mathrm{~nm}$ using UV/Vis spectrophotometer (UVIKON 942, Kontron Co, Italy). The TBARS values was calculated from a standard curve $(8 \sim 50 \mathrm{nmol})$ of malondialdehyde and defined as $m g$ of malondialdehyde per $\mathrm{kg}$ of sample.

\section{Cholesterol contents and Phagocytosis}

Blood samples for cholesterol and phagocytosis assay were collected via anterior vena cava puncture from 6 pigs per treatment at $2^{\text {nd }}$ weeks and $4^{\text {th }}$ weeks of feeding trial. After blood collection, blood samples were transferred into both non-heparinized tubes and vacuum tubes containing $\mathrm{K}_{2}$-EDTA (Becton Dickinson Co., Franklin Lakes, NJ) as an anticoagulant to obtain serum and whole blood, respectively. Serum total cholesterol was measured using commercial assay kits (Asan Co., Korea). The innate immune response was evaluated through measurement of reactive oxygen species produced during phagocytosis (respiratory burst) by porcine neutrophil. The blood for analysis of reactive oxygen species was collected using heparin containing tube to prevent blood clotting. Neutrophils were separated using Histopaque 1077 (Sigma Co.) and 1119 (Sigma Co.) from collected blood. Respiratory burst by neutrophil was measured using 6-channel luminometer (Biolumat LB 9505, Berthold, Wildbad, Germany)

\section{Olfactory analysis by electronic nose}

Flavor is the most important characteristic of meat quality perceived by the consumer. Sensory analysis of meat flavor has been evaluated by an expert panel. This method has some critical problems such as the subjectivity of human

Table 1. Formula and nutrients composition of the basal diet

\begin{tabular}{|c|c|}
\hline Ingredients & $\%$ \\
\hline Corn & 66.89 \\
\hline Wheat bran & 2.12 \\
\hline Corn germ meal & 5.00 \\
\hline Coconut. Exp. & 3.00 \\
\hline Palm kernel meal & 3.00 \\
\hline Soybean meal & 10.85 \\
\hline Rapeseed meal & 3.00 \\
\hline Dried soy-curd & 3.00 \\
\hline Treatment oils ${ }^{1)}$ & 1.00 \\
\hline Limestone & 0.73 \\
\hline T.C.P & 0.56 \\
\hline $\mathrm{NaCl}$ & 0.25 \\
\hline Lysine-HC1 & 0.25 \\
\hline Threonine & 0.06 \\
\hline Vitamin premix $^{2)}$ & 0.10 \\
\hline Mineral premix & 0.10 \\
\hline Choline-C1 & 0.10 \\
\hline Nutrients composition & $\%$ \\
\hline Moisture & 11.65 \\
\hline $\mathrm{DE}, \mathrm{kcal} / \mathrm{kg}$ & 3,350 \\
\hline C. Protein & 15.00 \\
\hline C. Fat & 5.02 \\
\hline EFA & 2.02 \\
\hline Lys. & 0.85 \\
\hline Met. & 0.26 \\
\hline Thr. & 0.58 \\
\hline Trp. & 0.16 \\
\hline
\end{tabular}

${ }^{1)}$ Supplemental oil source was changed according to the treatment designated as corn oil for Control, CLA rich oil for CLA, GLA rich primrose oil for GLA and the same GLA and $50 \mathrm{ppm}$ carnitine for GLA+Carnitine.

${ }^{2)}$ Contained the followings in $1 \mathrm{~kg}$; Vit. A, 80,000,000 IU; Vit. $\mathrm{D}_{3}$, 1,500,000 IU; Vit. E, 80,000 IU; Vit. K, 1,500 mg; Vit. B 1, 1,000mg; Vit. $B_{2}, 4,000 \mathrm{mg}$; Vit. $\mathrm{B}_{6}, 2,000 \mathrm{mg}$; Vit. $\mathrm{B}_{12}, 20 \mathrm{mg}$; Pantothenate, 12,000 mg; Niacin, 20,000 mg; Biotin, 100 mg; Folic Acid, 600 mg. 
response to odors and the variability between individuals. Thus, specific instrument such as the electronic nose that is an automated non-destructive technique to detect and distinguish odors precisely in complex food samples was introduced for food quality control(Peris and EscuderGilabert, 2009).

In this study, olfactory analysis of meat flavor was conducted using a metal-oxide semiconductor (MOS) based gas analyzer array electronic nose detector combined with a headspace autosampler (Fox 3000, Alpha M.O.S., Toulouse, France). Carrier gas dry air at $250 \mathrm{ml} / \mathrm{min}$ was used. Calibration of the sensors was carried out according to the manufacturer's instructions. Data were processed with the Alpha software. $1 \mathrm{~g}$ of ground meat samples were transferred into $10 \mathrm{ml}$ vials and incubated for $15 \mathrm{~min}$ at $40^{\circ} \mathrm{C}$ under agitation $(500 \mathrm{rpm})$. From the headspace, volumes of $1,000 \mu$ were automatically withdrawn by a gas tight syringe $(2.5 \mathrm{ml})$ kept at $55^{\circ} \mathrm{C}$ into detection chamber. The subsequent exposure time of the flow injected volume to the sensors was $2 \mathrm{~min}$ and the delay time between consecutive injections was $25 \mathrm{~min}$. Acquisition time was 150 seconds. Carrier and washing gas used in instruments was highly purified oxygen. All analyses were determined in triplicate.

\section{Statistical analysis}

Data were analyzed based on a randomized complete design using the general linear model (GLM) procedure of SAS (Ver. 8, SAS Inst., Inc., Cary, NC). Differences with $\mathrm{p}$ $<0.05$ were considered significant. Differences among means were determined using a multiple-range test. The pen served as the experimental unit for growth performances and the pig was the experimental unit for carcass trait, fatty acid and cholesterol content, phagocytosis and olfactory analyses.

\section{RESULTS AND DISCUSSION}

\section{Pig performance}

There was no significant difference in average daily gain (ADG), feed conversion ratio (FCR) and nutrient digestibility among pigs fed different functional fatty acids as shown in Table 2. However, the average daily feed intake (ADFI) was significantly $(\mathrm{p}<0.05)$ lower in pigs fed CLA supplemented diet than pigs fed GLA+Carnitine supplemented diet.

Dugan et al. (2004) concluded, after meta-analysis of 14 feeding studies, that the dietary CLA supplementation did not significantly affect pig growth.But $70 \%$ of such studies showed CLA supplementation did improve feed conversion ratio by $6.5 \%$ in average. In the present study, CLA supplementation also tended to improve FCR but it is believed to be resulted from the significantly lesser $(p<0.05)$ feed intake of CLA enriched diet. In a comparison between CLA and sunflower oil as supplemental oil, Dugan et al. (1997) also found a decrease in feed intake and improvement in feed efficiency although there was no difference in growth rate. The feed intake was also decreased in a chicken study (Yin et al., 2008) and pig study (White et al., 2009) although the production and feed efficiency were not changed.

The reasons of the effect of CLA on reducing feed intake has not clearly elucidated yet. Feed intake was known to be regulated by plethora of factors. Among them, blood glucose level for short term period and insulin and leptin levels for long term base have drawn serious attention(Carrol and

Table 2. Effect of dietary CLA, GLA and GLA + Carnitine supplementation on pig performance and nutrients digestibility of experimental diets

\begin{tabular}{ccccc}
\hline \multirow{2}{*}{ Items } & \multicolumn{3}{c}{ Diets } \\
\cline { 2 - 5 } & Control & CLA & GLA & GLA + Carnitine \\
\hline \hline Performance & & & \\
ADG (kg) & $0.81 \pm 0.13$ & $0.84 \pm 0.14$ & $0.86 \pm 0.06$ & $0.90 \pm 0.08$ \\
ADFI (kg) & $2.63 \pm 0.11^{\mathrm{ab}}$ & $2.43 \pm 0.19^{\mathrm{b}}$ & $2.85 \pm 0.20^{\mathrm{ab}}$ & $2.90 \pm 0.04^{\mathrm{a}}$ \\
FCR & $3.25 \pm 0.04$ & $2.89 \pm 0.20$ & $3.31 \pm 0.59$ & $3.22 \pm 0.13$ \\
\hline Digestibility (\%) & & & $77.69 \pm 6.07$ & $76.88 \pm 3.21$ \\
DM & $76.15 \pm 4.55$ & $73.79 \pm 1.63$ & $66.57 \pm 2.30$ & $67.31 \pm 5.92$ \\
N & $66.18 \pm 7.47$ & $64.28 \pm 1.62$ & $75.31 \pm 7.03$ & $74.58 \pm 3.69$ \\
Energy & $73.18 \pm 5.59$ & $70.85 \pm 2.67$ & & \\
\hline
\end{tabular}

\footnotetext{
${ }^{\mathrm{ab}}$ Means \pm SD with different superscripts within the same row differ $(\mathrm{p}<0.05)$.
} 
Allee, 2009; Greer et al., 2009). In a pig genetic study (Hoque et al., 2009), there was a strong correlations between residual feed intake and serum leptin concentration. Dietary CLA increased the serum leptin level in lactating sows (Bontempo et al., 2004) and blood glucose and insulin levels were higher with dietary $t 10 c 12$ CLA in rat studies (Kang and Pariza; 2001, Roche et al., 2002). Although this study did not measure the levels of the hormones and glucose, reduction in feed intake of CLA enriched diet could be explained by this mechanism. In addition, Latour et al. (2003) suggested CLA feeding may need acclimatization period for pigs to draw functional potential of the CLA. Since the feeding duration was only $28 \mathrm{~d}$ in this study, relatively short compared to other studies, lower feed intake in this study could also be explained, in part, by insufficient acclimatization.

\section{Carcass characteristics}

There were no differences $(\mathrm{p}<0.05)$ in conventional pork quality represented as backfat thickness and carcass grade of pigs fed diets supplemented with CLA or GLA with orwithout carnitine as shown in Table 3. Although CLA was known to decrease body fat, this generally represented as fat concentration in whole body not as specific backfat thickness. Therefore, responses on backfat thickness by dietary CLA have varied. In addition, feeding period and supplementation level of CLA also affected the response (Wiegand et al., 2001). Increased CLA level and feeding duration resulted remarkable decrease in backfat thickness. Relatively low CLA level and short feeding duration in this study could explain no difference in backfat thickness. Diet protein level interacted with CLA on backfat thickness (Moon et al., 2008) indicating no effect on backfat thickness with low protein diet.

Dietary GLA enrichment, although not significant, tended to decrease the thickness of backfat compared to other fatty
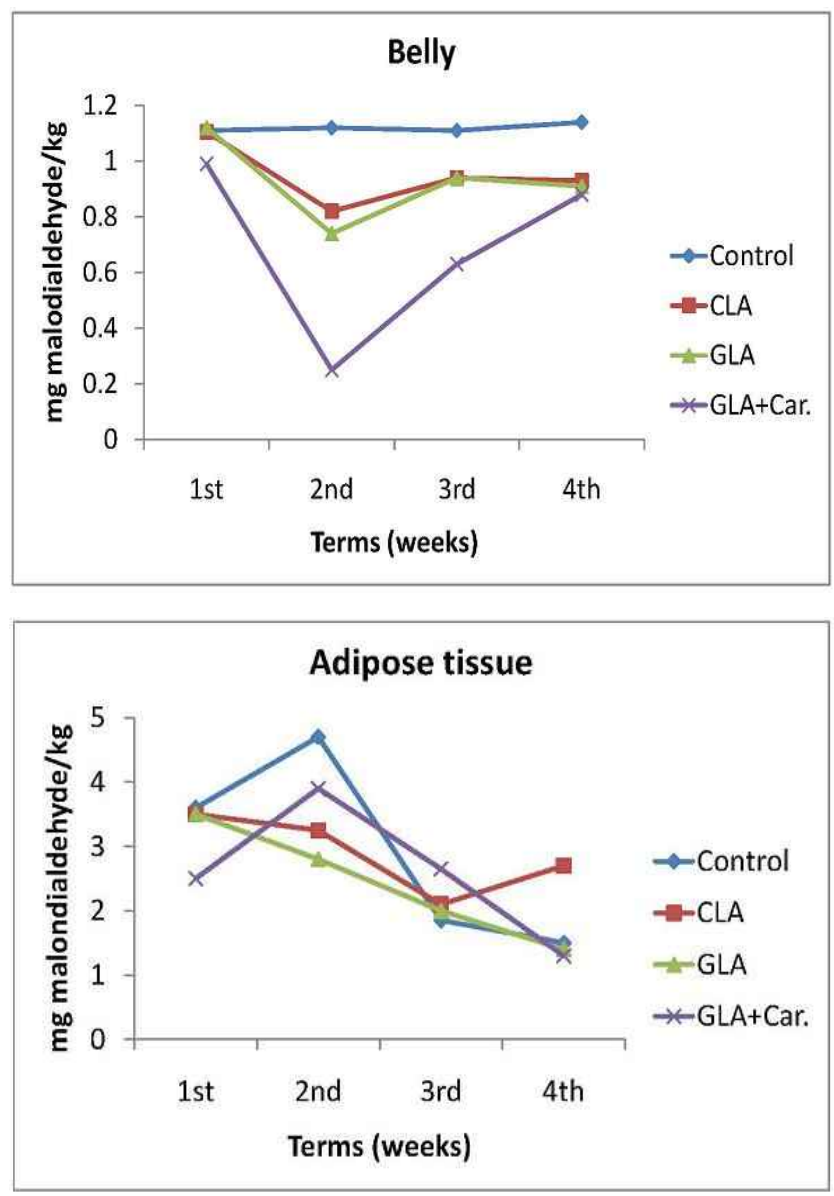

Fig. 1. Lipid oxidation characteristics of pork belly and adipose tissue. Initiation of lipid oxidation in belly was suppressed by dietary CLA, GLA and GLA + Carnitine supplementation, with highest magnitude by GLA + Carnitine. However the suppression became weaker with extended storage and in adipose tissue instead of belly. Magnitude of lipid oxidation in adipose tissue was stronger than that in belly. The rate of oxidation in adipose tissue was accelerated up to 2 weeks then slowed down with further storage. In belly, there was no such a change in the rate of oxidation with storage.

Table 3. Carcass characteristics of experimental pigs fed diets supplemented with either CLA, GLA or GLA + Carnitine

\begin{tabular}{lcccc}
\hline \multirow{2}{*}{ Items } & \multicolumn{3}{c}{ Diets } \\
\cline { 2 - 5 } & Control & CLA & GLA & GLA + Carnitine \\
\hline \hline Dressing percentage & $81.07 \pm 2.52$ & $79.57 \pm 1.41$ & $80.65 \pm 0.06$ & $80.37 \pm 1.19$ \\
Back fat thickness (mm) & $24.84 \pm 2.72$ & $24.18 \pm 1.49$ & $23.39 \pm 1.01$ & $24.10 \pm 2.58$ \\
Carcass grade $^{\mathrm{a}}$ & 2.0 & 2.2 & 2.0 & 2.1 \\
\hline
\end{tabular}

\footnotetext{
${ }^{a}$ Lower number indicates the better quality within the scale from 1 (grade A) to 4 (grade D) by Korea Pork Qualification Standard.
} 
acids supplementation. Although the backfat thickness decreased whereas lean percentage increased by dietary carnitine supplementation (Owen et al., 2001), this study did not show any further decrease in backfat thickness due to carnitine. Carnitine was proposed for doing a certain role to transport GLA to be expended as an energy source. In a pig study, the activity of liver carnitine palmitoyl transferase (CPT), the rate-limiting enzyme of mitochondrial fatty acid betaoxidation, was higher when GLA, instead of other oil, was supplemented to the diet (Takada and Saitoh, 1998). Since the CPT level was not measured in this study, it is difficult to confirm any significant mediation of carnitine in fatty acid transport. However, there was no difference between GLA only and GLA + Carnitine combined supplementation in terms of energy digestibility in Table 2 and back fat thickness in Table 3. This result is also well agreed with Menendez et al., (2005) who reported no significant change in carcass quality due to dietary carnitine.

\section{Serum cholesterol}

Serum cholesterol contents were not different $(p<0.05)$ among dietary treatments although the value tended to be decreased in pigs fed GLA supplemented diet. In a layer study (Furuse et al., 1992), both serum triglyceride and cholesterol tended to be decreased by dietary GLA which is similar to the present result. Fukushima et al. (2001) and Liu et al. (2004) also found a decrease in serum total cholesterol as well as LDL cholesterol in a study with older rats. However, the mode of GLA for cholesterol regulation was not clarified yet.

Many studies reported no significant effect of CLA on cholesterol contents. A few studies found a decrease in HDL cholesterol by CLA supplementation although total cholesterol levels remained unchanged. Since this study only measured the level of total cholesterol, it is difficult to mention any differences in HDL or LDL cholesterols.

In this study, there was no effect of dietary carnitine supplementation on blood total cholesterol level. Carnitine was reported to reduce LDL cholesterol in a human study (Malaguanara et al., 2009). However in study with alcoholic rabbit (Lin et al., 2010), the cholesterol level was surprisingly increased with dietary carnitine. These results implied that the carnitine may act differently according to the primary need of fatty acids in other parts of body.

\section{Change in pork TBARS value}

Weekly changes in TBARS values of pork belly and subcutaneous adipose tissue are shown in Fig. 1. There was a distinct difference in TBARS patterns between belly and adipose tissue. The values of adipose tissue were always higher than those of belly and time course changing pattern between belly and adipose tissue were also different. Dietary GLA + Carnitine enrichment was able to retard oxidation of pork at the early stage ( 1 week for adipose tissue and up to 2 weeks for belly). However, with extended storage, there was no difference among treatments. This result indicated that there would be a time limitation for the fatty acids to maintain their potential anti-oxidation efficacy. On the other hand, the expiring efficacy was presumed to be the result of expenditure of the accumulated fatty acids.

Increase in meat TBARS value was reported when the diet contained high PUFA (Gonzalez, 2008; Sioutis et al., 2008). Relatively higher TBARS in pork from pigs fed control corn oil could be attributed to its relatively higher (54 60\%) proportion of linoleic acid (C18:2, n-6) in corn oil (www.corn.org). Report on anti-oxidative potential of CLA has been varied. Higher dose of CLA often induced an increasing fatty acid peroxidation in pork (Martin et al., 2007) and in men(Raff et al., 2008). In this study, there was no CLA effect on retarding pork lipid peroxidation rather caused an increase in TBARS of adipose tissue after 4 weeks storage. These results suggested that it needs further researches to elucidate the role of CLA to prevent lipid peroxidation in both pork and live tissue.

Table 4. Serum cholesterol concentrations of pigs fed diets supplemented with either CLA, GLA or GLA+ Carnitine

\begin{tabular}{|c|c|c|c|c|}
\hline \multirow{2}{*}{ Time } & \multicolumn{4}{|c|}{ Diets } \\
\hline & Control & CLA & GLA & GLA+Carnitine \\
\hline & \multicolumn{4}{|c|}{$\mathrm{mg} / \mathrm{dl}$} \\
\hline 2nd week & $90.78 \pm 7.15$ & $90.12 \pm 16.09$ & $85.15 \pm 4.09$ & $91.84 \pm 14.10$ \\
\hline 4th week & $92.51 \pm 5.71$ & $90.77 \pm 8.86$ & $88.14 \pm 4.47$ & $89.40 \pm 11.29$ \\
\hline
\end{tabular}




\section{Fatty acids profiles of pork}

Relative proportions of fatty acids in diet and pork belly, loin, thin skirt and subcutaneous adipose tissue are shown in Table 5. Since the proportion values in the table were expressed as $\mathrm{mg}$ fatty acid in $\mathrm{g}$ fatty acid methyl ester (FAME), not sum of fatty acids, it is needed to consider this difference upon comparison with other reported values. In addition, there was no extended analysis of long chain fatty acids, which had more than 20 carbons in the chain. Many reports (Martin et al., 2007; Sioutis et al., 2008; Hanczakowski et al., 2009) had witnessed the total proportion of fatty acids higher than $\mathrm{C} 20$ was less than $2 \sim 2.5 \%$, regardless of dietary supplemental oils.

Relative percentage of saturated fatty acids such as C16:0 and $\mathrm{C} 18: 0$ was higher $(\mathrm{P}<0.05)$ in pork loin and thin skirt from pigs fed CLA enriched diet compared to those from other diets as shown in Table 5. On the other hand, the relative proportion of poly-unsaturated fatty acids (PUFA), C18:1 and C18:2 in pork were tended to be lower by dietary CLA enrichment. However, there was no such a trend in adipose tissue. Similar with this result, White et al. (2009) reported a decreased iodine value of pork backfat and Martin et al. (2007) reported an increased proportion of saturated fatty acids by dietary CLA addition. The lower iodine value indicates a decreased proportion of unsaturated fatty acids in the backfat. With comparison of fatty acid profile between diet and pork part, C18:2 was the highest fatty acid in pork, regardless of pork parts, although C18:2 was the highest fatty acid in the diet.

Compare to CLA, GLA was not effective to increase the proportion of saturated fatty acids (SFA) in this study. There was no difference in fatty acid profiles between GLA and control treatment although the GLA rich Spirulina feeding caused an increase in SFA in rabbit (Peiretti and Meineri, 2011). Dietary carnitine supplementation increased the proportion of SFA and mono-unsaturated fatty acids whereas decreased the proportion of PUFA in pork belly (Apple et al., 2011). However, in this study, there was no such effect of carnitine to increase saturation ratio although the GLA+ carnitine tended to increase the proportion of C18:0 compared to that of GLA only supplementation. Relatively higher proportion of C18:0 was distinct in adipose tissue in this study.

CLA and GLA deposition in pork was confirmed in this study as shown in Table 6. However, the rate of deposition compared to dietary load was higher with CLA than GLA. CLA contents in pork from pig fed CLA supplemented diet were higher than pork from pigs fed other diets. Among parts of pork, adipose tissue was highest for the accumulation of CLA whereas loin was lowest. Slight level of CLA deposit was confirmed in pork from pigs fed CLAfree control diet and GLA diets. This result witnessed the possible de novo synthesis of CLA in pig and confirmed an average $0.1 \sim 0.2 \mathrm{mg} \mathrm{CLA} / \mathrm{g}$ fat accumulation in pork without CLA enrichment (Dugan et al., 2004). He et al. (2005) and Martin et al. (2007) also reported average 0.18\% CLA accumulation in pork adipose tissue without any dietary CLA enrichment. However, there was no such CLA accumulation by GLA+Carnitine supplementation, although it was observed in GLA only supplemented pigs. This would be associated with the specific role of carnitine. Carnitine was known to prevent depots of certain fatty acid therefore destabilize muscle cell membrane (Hemat, 2004).

Ratio of CLA accumulation among parts of pork has drawn attention. Once CLA was not supplemented to diet, the ratio of accumulation was not different between intramuscular and subcutaneous fat (He et al., 2005; Table 5 in this study). However, the ratio of CLA accumulation in subcutaneous adipose tissue was higher than that in loin once fed CLA enriched diet, which is identical to the result of Ramsey et al. (2001). The average percent of CLA accumulation in this study was lower than the average values in previous report (Martin et al., 2007). Since the CLA accumulation into the pork has been well associated to the dietary level of CLA in dose dependent manner (Dugan et al., 2004; Ramsey et al., 2001), the low accumulation rate could be attributed to the relatively less CLA dose in this study.

GLA was also accumulatedinto porcine adipose tissue by feeding GLA-enriched diet. However the average level of GLA in the pork was relatively lower than that of CLA in Table 6. It is relatively difficult to find data reporting GLA concentration in pork. In guinea pig study, Chung et al. (2002) failed to find any accumulation of GLA in epidermis but found an accumulation of dihomo-gamma linolenic acid (DGLA), an elongated form of fatty acid from GLA. There was an increase of GLA and DGLA in serum and neutrophils of human after dietary GLA consumption (Weaver et al, 2009). Recently, Peiretti and Meineri (2011) reported GLA accumulation into longissimus dorsi muscle and adipose tissue of rabbit fed GLA enriched diets. However, Hanczakkowski et al. (2009) reported no GLA accumulation 
Table 5. Fatty acids profile of experimental diets and pork from pigs fed either CLA, GLA or GLA + Carnitine enriched experimental diets

\begin{tabular}{|c|c|c|c|c|}
\hline \multirow{2}{*}{ Pork and fatty acids } & \multicolumn{4}{|c|}{ Diets } \\
\hline & Control & CLA & GLA & GLA + Carnitine \\
\hline & \multicolumn{4}{|c|}{$m g$ fatty acid/ $g$ FAME } \\
\hline \multicolumn{5}{|l|}{ Diet } \\
\hline Lauric acid (C12:0) & 141.7 & 113.1 & 157.9 & 159.6 \\
\hline Palmitic acid (C16:0) & 110.7 & 84.1 & 98.9 & 102.4 \\
\hline Stearic acid (C18:0) & 18.5 & 14.1 & 13.7 & 17.5 \\
\hline Oleic acid $(\mathrm{C} 18: \ln 9 \mathrm{c})$ & 204.4 & 155.2 & 162.3 & 161.9 \\
\hline Linoleic acid (C18:2n6c) & 425.4 & 290.3 & 446.8 & 440.3 \\
\hline GLA $(\mathrm{C} 18: 3 \mathrm{n} 6)$ & $\mathrm{N} / \mathrm{D}^{1)}$ & N/D & 11.6 & 13.8 \\
\hline Linolenic acid (C18:3n3) & 8.7 & 11.5 & N/D & $\mathrm{N} / \mathrm{D}$ \\
\hline \multicolumn{5}{|l|}{ Pork belly } \\
\hline Lauric acid (C12:0) & 61.4 & 63.4 & 57.0 & 47.9 \\
\hline Palmitic acid (C16:0) & 230.6 & 239.6 & 239.4 & 217.4 \\
\hline Stearic acid (C18:0) & 81.1 & 135.3 & 114.1 & 122.5 \\
\hline Oleic acid $(\mathrm{C} 18: \ln 9 \mathrm{c})$ & 402.2 & 364.4 & 387.4 & 420.3 \\
\hline Linoleic acid (C18:2n6c) & 121.1 & 112.1 & 115.3 & 114.1 \\
\hline GLA $(\mathrm{C} 18: 3 \mathrm{n} 6)$ & $\mathrm{N} / \mathrm{D}$ & N/D & $\mathrm{N} / \mathrm{D}$ & N/D \\
\hline Linolenic acid (C18:3n3) & $\mathrm{N} / \mathrm{D}$ & $\mathrm{N} / \mathrm{D}$ & 1.0 & 2.1 \\
\hline \multicolumn{5}{|l|}{ Pork loin } \\
\hline Lauric acid (C12:0) & 112.0 & 66.6 & 64.3 & 48.0 \\
\hline Palmitic acid (C16:0) & $209.0^{\mathrm{b}}$ & $266.8^{\mathrm{a}}$ & $217.6^{b}$ & $225.0^{\mathrm{b}}$ \\
\hline Stearic acid (C18:0) & 112.3 & 117.0 & 116.4 & 119.4 \\
\hline Oleic acid $(\mathrm{C} 18: \ln 9 \mathrm{c})$ & 340.1 & 372.0 & 366.8 & 412.7 \\
\hline Linoleic acid (C18:2n6c) & 123.0 & 94.3 & 109.9 & 105.9 \\
\hline GLA $(\mathrm{C} 18: 3 \mathrm{n} 6)$ & $\mathrm{N} / \mathrm{D}$ & N/D & N/D & 0.4 \\
\hline Linolenic acid (C18:3n3) & 2.1 & 1.1 & $\mathrm{~N} / \mathrm{D}$ & 6.4 \\
\hline \multicolumn{5}{|l|}{ Pork thin skirt } \\
\hline Lauric acid (C12:0) & 74.0 & $\mathrm{~N} / \mathrm{D}$ & 55.6 & 60.4 \\
\hline Palmitic acid (C16:0) & $230.5^{\mathrm{b}}$ & $271.5^{\mathrm{a}}$ & $215.7^{\mathrm{b}}$ & $234.7^{\mathrm{b}}$ \\
\hline Stearic acid (C18:0) & 121.1 & 131.1 & 112.8 & 127.8 \\
\hline Oleic acid $(\mathrm{C} 18: \ln 9 \mathrm{c})$ & 349.9 & 356.7 & 377.9 & 383.1 \\
\hline Linoleic acid (C18:2n6c) & 145.3 & 130.3 & 133.4 & 138 \\
\hline GLA $(\mathrm{C} 18: 3 \mathrm{n} 6)$ & $\mathrm{N} / \mathrm{D}$ & $\mathrm{N} / \mathrm{D}$ & N/D & $\mathrm{N} / \mathrm{D}$ \\
\hline Linolenic acid (C18:3n3) & $\mathrm{N} / \mathrm{D}$ & $\mathrm{N} / \mathrm{D}$ & 3.6 & $\mathrm{~N} / \mathrm{D}$ \\
\hline \multicolumn{5}{|l|}{ Adipose tissue } \\
\hline Lauric acid (C12:0) & 29.9 & 25.7 & 34.0 & 29.2 \\
\hline Palmitic acid (C16:0) & 226.2 & 230.1 & 250.1 & 210.8 \\
\hline Stearic acid (C18:0) & 106.6 & 127.2 & 56.9 & 126.9 \\
\hline Oleic acid $(\mathrm{C} 18: \ln 9 \mathrm{c})$ & 432.2 & 386.8 & 438.1 & 409.1 \\
\hline Linoleic acid (C18:2n6c) & 133.0 & 138.1 & 139.3 & 151.1 \\
\hline GLA (C18:3n6) & N/D & N/D & N/D & 0.2 \\
\hline Linolenic acid (C18:3n3) & $\mathrm{N} / \mathrm{D}$ & $\mathrm{N} / \mathrm{D}$ & $\mathrm{N} / \mathrm{D}$ & 1.6 \\
\hline
\end{tabular}

1) not-detectable. 
Table 6. CLA and GLA deposit comparison between diet and pork parts

\begin{tabular}{|c|c|c|c|c|}
\hline \multirow{2}{*}{ Pork parts } & \multicolumn{4}{|c|}{ Diets } \\
\hline & Control & CLA & GLA & GLA+ Carnitine \\
\hline \multicolumn{5}{|c|}{ CLA (mg CLA/g FAME) } \\
\hline Diet & $\mathrm{N} / \mathrm{D}^{1)}$ & 43.0 & $\mathrm{~N} / \mathrm{D}$ & $\mathrm{N} / \mathrm{D}$ \\
\hline Belly & 0.9 & 4.2 & 1.2 & $\mathrm{~N} / \mathrm{D}$ \\
\hline Loin & $\mathrm{N} / \mathrm{D}$ & 2.0 & 1.3 & $\mathrm{~N} / \mathrm{D}$ \\
\hline Skirt & $\mathrm{N} / \mathrm{D}$ & 4.3 & 0.0 & $\mathrm{~N} / \mathrm{D}$ \\
\hline Adipose tissue & 1.0 & 6.6 & 1.1 & $\mathrm{~N} / \mathrm{D}$ \\
\hline \multicolumn{5}{|c|}{ GLA (mg GLA/g FAME) } \\
\hline Diet & $\mathrm{N} / \mathrm{D}$ & $\mathrm{N} / \mathrm{D}$ & 11.6 & 13.8 \\
\hline Belly & $\mathrm{N} / \mathrm{D}$ & $\mathrm{N} / \mathrm{D}$ & $\mathrm{N} / \mathrm{D}$ & $\mathrm{N} / \mathrm{D}$ \\
\hline Loin & $\mathrm{N} / \mathrm{D}$ & $\mathrm{N} / \mathrm{D}$ & $\mathrm{N} / \mathrm{D}$ & 0.4 \\
\hline Skirt & $\mathrm{N} / \mathrm{D}$ & $\mathrm{N} / \mathrm{D}$ & $\mathrm{N} / \mathrm{D}$ & $\mathrm{N} / \mathrm{D}$ \\
\hline Adipose tissue & $\mathrm{N} / \mathrm{D}$ & $\mathrm{N} / \mathrm{D}$ & 0.3 & 0.2 \\
\hline
\end{tabular}

${ }^{1)}$ not-detectable.

in pork from pigs fed diets without GLA enrichment. After L-carnitine mediated the transport of fatty acids across mitochondrial membrane, it also prevented the accumulation of the fatty acids via simultaneous $\beta$-oxidation (Hemat, 2004). This result implied that the L-carnitine mediated transport of GLA may result in the accumulation of GLA only if the fatty acid was not $\beta$-oxidized further for energy generation. In this study, however, there was GLA accumulation in loin by additional carnitine supplementation but not by GLA only supplementation. This result may suggest that the carnitine mediated GLA transport could be more distinct in loin than adipose tissue.

\section{Phagocytosis of neutrophil}

Phagocytic activity was highest $(\mathrm{p}<0.05)$ in neutrophil of pigs fed GLA + Carnitine supplemented diet, followed by pigs fed GLA supplemented diet as shown in Fig. 2. In this study, the phagocytic activity of pigs fed CLA enriched diet was lower $(p<0.05)$ than GLA groups and even tended to be lower than that of control. Phagocytosis has been considered as one of the index of innate immune response (Liu et al, 1999). Neutrophil was known as a critical component of the innate immune response and primarily employed to defend against invading microorganisms.

The phagocytic activity however, needs energy to execute normal immune function (Chandak et al., 2010). Since immune cells like neutrophil possess lipoprotein receptor, PUFA in phospholipid positively affected the phagocytosis (Kew et al.,

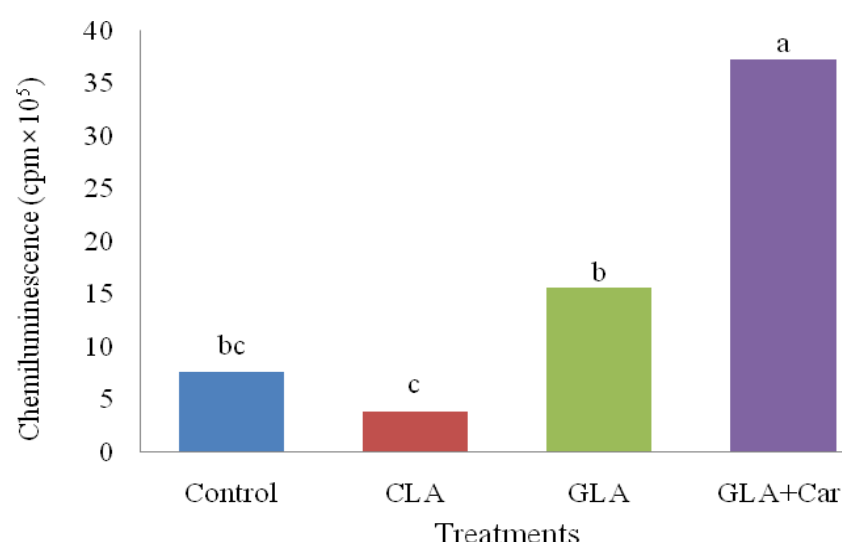

Fig. 2. Phagocytic activities of neutrophil from pigs fed diets supplemented with CLA, GLA with or without carnitine. The phagocytosis was highest in pigs fed GLA + Carnitine supplemented diet then followed by GLA supplemented diet. The result indicated that stimulation by GLA was more remarkable than that by CLA for the innate immune response of neutrophil and there is a further encouragement by carnitine possibly through fatty acids energy mobilization in pig. As noted, CLA supplementation failed to improve rather decreased the phagocytic activity. ( ${ }^{\text {abc }}$ indicated significant difference at $\mathrm{p}<0.05$ ).

2003). It was proposed that the immune cells can metabolize PUFAs (Riediger et al., 2009) and can modify the fatty acid composition of their plasma membrane (Yaqoob, 2004). In this regard, CLA, GLA and carnitine (Hoppel et al., 2003; Izgüt-Uysal et al., 2004) as the fatty acid transporter were 
expected to benefit the degree of phagocytosis. Increase in phagocytosis by GLA and further with carnitine in this study could be explained by this increased energy supply to neutrophil phagocytosis. Chandak et al. (2010) also supported the role of carnitine palmitoyl- transferase in mitochondrial fatty acid $\beta$-oxidation.

CLA is known to be associated with an immune response in pigs (Bontempo et al., 2004) and in humans (Stachowska et al., 2007), resulting increased macrophage phagocytosis. Inhibition of prostaglandin $\mathrm{E}_{2}\left(\mathrm{PGE}_{2}\right)$ synthesis was proposed to be related with an enhanced the peritoneal macrophage phagocytosis (Stachowska et al., 2007) However, when peroxisome proliferator-activated receptor $\gamma(\operatorname{PPAR} \gamma)$ antagonist was activated, the CLA treatment inhibited the phagocytic activity (Song et al., 2007). Relationship between CLA and phagocytosis is presumed to be bidirectional (Ecker et al., 2010), and frequently exerted contradictory results upon the same CLA supplementation. CLA was able to stimulate (Ge et al., 2009) or suppress the ability of macrophage inhibited interleukin-2 production (a desirable cytokine) and suppressed the ability of macrophages. Mice fed CLA had experienced an increase in fat cell apoptosis (Kang and Pariza, 2001). In addition, there would be a different mode of modulation by CLA between blood and in the skin.

Efficiency of CLA transport to the blood was also proposed to explain the decrease in phagocytosis in this study. In a review (McLeod et al., 2004) of many CLA supplementation studies, CLA resulted variable effects on plasma lipid. Therefore, the neutrophil in this study probably could not accumulate the fatty acids for energy supply. Since the ratio of saturated fatty acids to PUFAs was negatively correlated with the immune function (Kew et al., 2003), slight increaseof saturation by CLA in Table 5 , could be attributed to explain the lower phagocytosis by CLA.

However the role of specific fatty acid could not be clearly explained. Eicosapentaenoic acid (EPA) and GLA consumption did not alter neutrophil phagocytosis in human (Miles et al., 2004). GLA has also demonstrated somewhat confusing immune responses. Recently, there was a report (Lima-Salgado et al., 2011) which supported the bidirectional role of the specific fatty acids, such as CLA and GLA, for the mediation of host defence mechanism.

\section{Flavors of pork}

There were distinct differences in the flavor of pork from pigs fed different functional fatty acids as shown in Fig. 3. Since the flavor of pork was observed by electronic nose response, the distribution of flavor neither represented any human preference nor the preferred characteristic of flavor. But the distribution clearly implied there are distinct differences in flavor probably in terms of characteristic and intensity. The magnitude of differences in electronic nose response was greater in belly and loin than that of adipose tissue. In addition, the patterns of distribution were similar between belly and loin, which were different from pattern of adipose tissue. Since the adipose tissue is relatively homogenous with only fat, less degree of flavor distribution could be explained by this presumption.

Flavor of pork was known to be mostly associated with specific fatty acid concentration in pork (Cameron and Enser, 1991). In general, higher poly unsaturated fatty acids were tended to cause off-flavor while saturated fatty acids ameliorated that off-flavor in pork (Ellis and McKeith, 2010). Dietary fish oils or flaxseed and linseedoils has led to an increase in omega-3 fatty acid concentrations in the fat depots but has also caused an off flavor in pork probably as a result of lipid oxidation (Romans et al., 1995a, 1995b). Pork off flavor became higher with increasing level of linoleic acid along with decreasing level of palmitic acid. In Table 5, palmitic acid concentration was highest in pork from CLA supplementation while linoleic acid concentration was highest in control pork. If there was no significant difference in linoleic acid of pork, there was no flavor difference in pork although the diet was supplemented with fish meal (Sioutis et al., 2008).

Difference in these fatty acids concentration was presumed to be responsible in part for the difference in electronic nose pattern as shown in Fig. 3. Contribution of polyunsaturated fatty acids for flavor enhancement has been generally negative while that of saturated fatty acids has been positive. The higher generation of abnormal flavors could be explained by the higher level of unsaturated fatty acid which is more liable to generate rancidity.

However, there has been also a little bit confusing information on the organoleptic quality of pork especially in terms of flavor. Feeding strongly smelly ingredients often resulted off flavor in pork. Dietary fish oil caused a fishy taint in pork (Maw et al., 2001), fermented feed caused a rancid and off flavor (Hansen et al., 2000) and dietary inulin + rapeseed supplementation decreased aroma (Hansen et al, 2002). However the same fish oil did not result any difference 


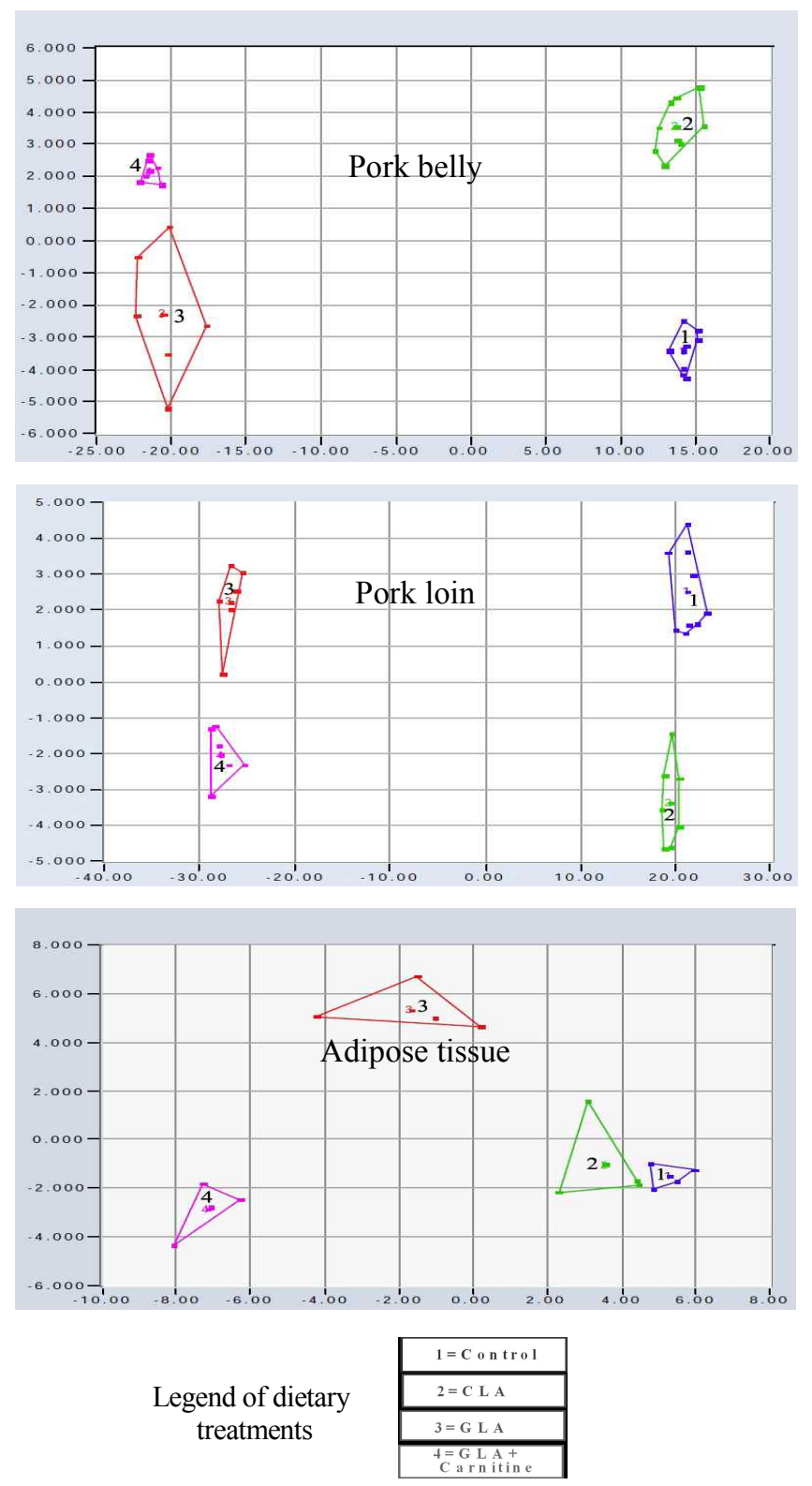

Fig. 3. Electronic nose flavor characteristics of pork belly, loin and adipose tissue. Three figures showed there are distinct differences in flavor type and intensity due to dietary CLA, GLA and GLA + Carnitine supplementation regardless of the part of pork. In addition, the difference presumed to be more remarkable in belly and loin compared to adipose tissue. However, these flavor differences do not represent any sensory preference by human to the type of flavor as well as its intensity.

in flavor once the diet was supplemented with a-tocopherol (Jonsdottir et al., 2003). Not much information is available on the flavor characteristic of pork fed diets supplemented with specific fatty acids. Most of studies with dietary vegetable oils and butter did not induce significant change in pork flavor (Teye et al., 2006 Ngapo and Gariepy, 2008). However, one 2\% CLA supplementation reported an increased intensity of flavor (Migdal et al., 2004), whereas other CLA studies (Dugan et al., 1999; Wiegand et al., 2001) reported no difference in flavor. These results implied that it is worth conducting further researches combining human and mechanical evaluation to practically characterize the flavor of pork.

\section{IMPLICATIONS}

To improve sensory and nutritional quality of pork, dietary enrichment of CLA and GLA could be successfully implemented since both fatty acids exerted its own characteristic benefit in terms of CLA and GLA deposit and TBARS of pork. However, it is needed not to anticipate nutraceutically effective accumulation of such fatty acids to the pork referring to the level of dietary dose.

\section{ACKNOWLEDGEMENT}

This research was partially supported by the Institute of Animal Resources, Kangwon National University, Republic of Korea.

\section{REFERENCES}

A. O. A. C. 1990. Official Methods of Analysis (15th ed.). Association of Official Analytical Chemists. Washington, D.C. Apple, J., Sawyer, J. T., Maxwell, C. V., Yancey, J. W. S., Frank, J. W., Woodworth, J. C. and Musser, R. E. 2011. Effects of 1-carnitine supplementation on quality characteristics of fresh pork bellies from pigs fed three levels of corn oil. J. Anim. Sci. on line. doi:10.2527/jas.2011-3933.

Bee, G. 2001. Dietary conjugated linoleic acids affect tissue lipid composition but not de novo lipogenesis in finishing pigs. Anim. Res. 50:383-399.

Bertol, T. M., Ellis, M., Hamilton, D. N., Johnson, E. W. and Ritter, M. J. 2005. Effects of dietary supplementation with L-carnitine and fat on blood acid-base responses to handling in slaughter weight pigs. J. Anim. Sci. 83:75-81.

Bontempo, V., Sciannimanico, D., Pastorelli, G., Rossi, R., Rosi, F. and Corino, C. 2004. Dietary conjugated linoleic acid positively affects immunologic variables in lactating sows and 
piglets. J. Nutr. 134:817-824.

Cameron, N. and Enser, M. 1991. Fatty acid composition of lipid in longissimus dors imuscle of Duroc and British Landrace pigs and its relationship with eating quality. Meat Science 29:295-307.

Carroll, J. A. and Allee, G. L. 2009. Hormonal control of feed intake in swine. In) Voluntary Feed Intake in Pigs. pp. 155-187 ISBN 978-90-8686-096-8.

Chandak, P., Radovic, B. Aflaki, E., Kolb, D., Buchebner, M., Frohlich, E., Magnes, C., Sinner, F., Haemmerle, G., Zechner, R., Tabas, I., Levak-Frank, S. and Kratky, D. 2010. Efficient phagocytosis requires triacylglycerol hydrolysis by adipose triglyceride lipase. J. Biol. Chem. 285:20192-20201.

Chung, S., Kong, S., Seong, K. and Cho, Y. 2002. V-Linolenic acid in borage oil reverses epidermal hyperproliferation in Guinea pigs. J. Nutr. 132: 3090-3097.

Dodson, V., Hausman, G., Guan, L., Du, M., Rasmussen, T., Poulos, S., Mir, P., Bergen, W., Fernyhough, M., McFarland, D., Rhoads, R., Soret, B., Reecy, J., Velleman, S. and Jiang, Z. 2010. Lipid metabolism, adipocyte depot physiology and utilization of meat animals as experimental models for metabolic research. Int. J. Biol. Sci. 6:691-699.

Dugan, M. E. R., Aalhus, J. L. and Kramer, J. K. G. 2004. Conjugated linoleic acid pork research. Am. J. Clin. Nutr. 79 (suppl):1212S-1216S.

Dugan, M. E. R., Aalhus, J. L., Schaefer, A. L. and Kramer, J. K. G. 1997. The effect of conjugated linoleic acid on fat to lean repartitioning and feed conversion in pigs. Can. J. Anim. Sci. 77:723-725.

Dugan, M. E. R., Aalhus, J. L., Jeremiah, L. E., Kramer, J. K. G. and Schaefer, A. L. 1999. The effects of feeding conjugated linoleic acid on subsequent pork quality. Can. J. Anim. Sci., 79:45-51.

Ecker, J., Liebisch, G., Scherer, M. and Schmitz, G. 2010. Differential effects of conjugated linoleic acid isomers on macrophage glycerophospholipid metabolism. J. Lipid Res. 51:2686-2694.

Eggert, J. M., Belury, M. A., Kempa-Steczko, A., Mills, S. E. and Schinckel, A. P. 2001. Effects of conjugated linoleic acid on the belly firmness and fatty acid composition of genetically lean pigs. J Anim. Sci. 79:2866-2872.

Ellis, M. and Mckeith, F. 2010. Nutritional influences on pork quality. http://www.extension.org/pages/27434/nutritionalinfluences-on-pork-quality.

Fenton, T. W. and Fenton, M. 1979. An improved procedure for the determination of chromic oxide in feed and feces. Can. J.
Anim. Sci. 59, 631-634.

Folch, J., Lees, M. and Sloane Stanley, G. H. 1957. A simple method for the isolation and purification of total lipids from animal tissues. J. Biol. Chem. 226:497-509.

Fukushima, M., Ohhashi, T., Ohno, S., Saitoh, H., Sonoyama, K., Shimada, K., Sekikawa, M. and Nakano, M. 2001. Effects of diets enriched in n-6 or n-3 fatty acids on cholesterol metabolism in older rats chronically fed a cholesterol-enriched diet. Lipids. 36:261-266.

Furuse, M., Okada, R., Kita, K., Asakura, K. and Okumura, J. 1992. Effect of gamma linolenic acid on lipid metabolism of laying hens. Comp. Biochem. Physiol. A 101: 167-169.

Ge, J., Wang, Y., Feng, Y., Liu, H., Cuil, X., Chen, F., Tai1, G. and Liu1, Z. 2009. Direct effects of activin A on the activation of mouse macrophage. Cell. Mol. Immunol. 6: 129-133.

Gonzalez, D. 2008. Effect of dietary fatty acids, time of feeding and immune response in poultry. MS thesis, Oregon state Univ. USA.

Greer, W., Boisclair, R., Stankiewicz, M., McAnulty, W., Jay, P., and Sykes, R. 2009. Leptin concentrations and the immunemediated reduction of feed intake in sheep infected with the nematode Trichostrongylus colubriformis. Br. J. Nutr. 102:954957.

Hanczakkowski, P., Szymczyk, B. and Hanczakowska, E. 2009. Fatty acid profile and cholesterol content of meat from pigs fed different fats. Ann. Anim. Sci. 9:157-163.

Hansen, L., Mikkelsen, L., Agerhem, H., Laue, A., Jensen, M. and Jensen, B. 2000. Effect of fermented liquid food and zinc bacitracin on microbial metabolism in the gut and sensoric profile of M. longissimus dorsi from entire male and female pigs. Anim. Sci. 71:65-80.

He, M. L., Ishikawa, S. and Hidari, H. 2005. Fatty acid profiles of various muscles and adipose tissues from fattening horses in comparison with beef cattle and pigs. Asian-Aust. J. Anim. Sci. 18:1655-1661.

Hemat, R. 2004. Principle of Orthomolecularism. Urotext. ISBN 1-903737-06-0.

Hoppel, C. 2003. The role of carnitine in normal and altered fatty acid metabolism. Am. J. Kidney Dis. 41S:4-12.

Hoque, A., Katoh, K. and Suzuki, K. 2009. Genetic associations of residual feed intake with serum insulin-like growth factor-I and leptin concentrations, meat quality, and carcass cross sectional fat area ratios in Duroc pigs J. Anim. Sci. 87:3069-3075.

Izgüt-Uysal V. N., Agaç, A., Karadogan, I. and Derin, N. 2004. Peritoneal macrophages function modulation by L-carnitine in 
aging rats. Aging Clin. Exp. Res.16:337-341.

James, B. W. 2009. Effects of dietary L-carnitine on finishing pig growth performance, meat quality and stress parameters during handling. Ph. D. Dissertation. KSU. USA.

Jonsdottir, R., Valdimarsdottir, T., Baldursdottir, B. and Thorkelsson, G. 2003. Influence of low fat fishmeal on fatty acid composition and sensory quality of pork. J. Muscle Foods. 14:51-56

Joo, S. T., Lee, J. I., Ha, Y. L. and Park, G. B. 2002. Effects of dietary conjugated linoleic acid on fatty acid composition, lipid oxidation, color, and water-holding capacity of pork loin. J. Anim. Sci. 80:108-112.

Kang, K. W. and Pariza, M. W. 2001. Trans-10,cis-12-conjugated linoleic acid reduces leptin secretion from 3T3-L1 adipocytes. Biochem. Biophy. Res. Comm. 287:377-382.

Kew, S., Banerjee, T., Minihane, A. M., Finnegan, Y. E., Williams, C. M. and Calder, P. C. 2003. Relation between the fatty acid composition of peripheral blood mononuclear cells and measures of immune cell function in healthfree-living subjects aged 25-72 y. Am. J. Clin. Nutr. 77:1278-1286.

Latour, M. A., Gerrard, D. E. and Shipp, T. E. 2003. Evaluating growth and carcass characteristics of barrows fed a triglyceride form of conjugated linoleic acid. Purdue Univ. Swine Res. Rep. 2003:68-71.

Lima-Salgado, T. M., Sampaio, S. C., Cury-Boaventura, M. F. and Curi, R. 2011. Modulatory effect of fatty acids on fungicidal activity, respiratory burst and TNF-a and IL-6 production in J774 murine macrophages. Br. J. Nutr. 105:1173-1179.

Lin, Y., Li, W., Ling, J. and Zhou, L. 2010. Effect of carnitine onserum cholesterol of alcoholic cardiomyopathy dogs. Eur. J. Lipid Sci. Technol. 112:821-827.

Liu, B. F., Miyata, S., Kojima, H., Uriuhara, A., Kusunoki, H., Suzuki, K., and Kasuga, M. 1999. Low phagocytic activity of resident peritoneal macrophages in diabetic mice: relevance to the formation of advanced glycation end products. Diabetes. 48:2074-2082.

Liu, J. W., DeMichele, S. J., Palombo, J. T., Chuang, L. T., Hastilow, C., Jr. Bobik, E. and Huang, Y. S. 2004. Effect of long-term dietary supplementation of high-gamma-linolenic canola oil versus borage oil on growth, hematology, serum biochemistry, and N-6 fatty acid metabolism in rats. J Agric Food Chem. 52:3960-3966.

Lykkesfeldt, J. and Svendsen, O. 2007. Oxidants and antioxidants in disease: oxidative stress in farm animals. Vet. J. 173:502511.

McLeod, R., LeBlanc, A., Langille, M., Mitchell, P. and Currie, D.
2004. Conjugated linoleic acids, atherosclerosis, and hepatic very-low-density lipoprotein metabolism. Am. J. Clin. Nutr. 79: 1169S-1174S.

Malaguarnera, M., Vacante, M., Avitabile, T., Malaguarnera, M., Cammalleri, L. and Motta, M. 2009. L-Carnitine supplementation reduces oxidized LDL cholesterol in patients with diabetes. Am. J. Clin. Nutr. 89:71-76.

Martin, D., Antequera, T., Gonzalez, E., Lopez-Bote, C. and Ruiz, J. 2007. Changes in the fatty cid profile of the subcutaneous fat of swine throughout fattening as affected by dietary conjugated linoleic acid and monounsaturated fatty acids. J. Agric. Food Chem. 55:10820-10826.

Maw, S. J., Fowler, V., Hamilton, M. and Petchey, A. 2001. Effect of husbandry and housing of pigs on the organoleptic properties of bacon. Livest. Prod. Sci., 68:119-130.

Menendez, A., Colomer, R. and Lupu, R. 2005. Inhibition of fatty acid synthase-dependent neoplastic lipogenesis as the mechanism of $\gamma$-linolenic acid-induced toxicity to tumor cells: an extensionto Nwankwo's hypothesis, Hypotheses 64:337-341.

Migdal, W., Pasciak, P., Wojtysiak, D., Barowicz, T., Pieszka, M. and Pietras, M. 2004. The effect of dietary CLA supplementation on meat and eating quality, and the histochemical profile of the m. longissimus dorsi from stress susceptible fatteners slaughtered at heavier weights. Meat Sci., 66:863-870.

Miles, E., Banerjee, T., Dooper, M., M'Rabet, L., Graus, Y. and Calder, P. 2004. The influence of different combinations of gamma-linolenic acid, stearidonic acid and EPA on immune function in healthy young male subjects. Br. J. Nutr. 91:893-903.

Miner, L., Cederbergy, C., Chenz, X., Baile, C. and Nielsenyy, M. 2001. Dietary conjugated linoleic acid (CLA) and body fat changes. Nebraska Swine Report:27-28.

Moon, H. K., Lee, S. D., Jung, H. J., Kim, Y. H., Park, J. C., Ji, S. Y., Kim, C. D., Kwon, O. S. and Kim, I. C.. 2008. Effects of dietary protein level and supplementation of conjugated linoleic acid on growth performance and meat quality parameters in finishing pigs. J. Anim. Sci. Technol. 50:695704.

Moreno, R., Miller, P., Burkey, T., Jones, S., Cuppett, S., Carr, T., Jones, T. and Diedrichsen, R. 2008. The effect of corn distillers dried grain with solubles (DDGS) on carcass characteristics and pork quality. Nebraska Swine Report. 2008:8-11.

Ngapo, T. and Gariepy, C. 2008. Factors affecting the eating quality of pork. Crit. Rev. Food Sci. Nutr. 48:599-633.

N. R. C. 1998. Nutrients Requirements of Swine. 10th ed. National 
Academy Science-National Research Council. Washington, D.C.

O'Shea. M., Bassaganya-Riera, J. and Mohede, I. 2004. Immunomodulatory properties of conjugated linoleic acid. Am. J. Clin. Nutr. 79: 1199S-1206S.

Owen, K. Q., Ji, H., Maxwell, C. V., Nelssen, J. L., Goodband, R. D., Tokach, M. D., Tremblay, G. C. and Koo, S. I. 2001. Dietary L-carnitine suppresses mitochondrial branched chain keto acid dehydrogenase activity and enhances protein accretion and carcass characteristics of swine. J. Anim. Sci. 79:31043112 .

Palombo, J. D., DeMichele, S. J., Liu, J. W., Bistrian, B. R. and Huang, Y. S. 2000. Comparison of growth and fatty acid metabolism in rats fed diets containing equal levels of gamma-linolenic acid from high gamma-linolenic acid canola oil or borage oil. Lipids. 35:975-981.

Peiretti, P. and Meineri, G. 2011. Effects of diets with increasing levels of Spirulina platensis on the carcass characteristics, meat quality and fatty acid composition of growing rabbits. Livestock Sci. doi:10.1016/j.livsci.2011.03.31.

Peris, M. and Escuder-Gilabert, L. 2009. A $21^{\text {st }}$ century technique for food control: Electronic nose. Analytica Chimica Acta. 638:1-15.

Raff, M., Tholstrup, T., Basu, S., Nonboe, P., Sørensen, M. and Straarup, E. 2008. Diet rich in conjugated linoleic acid and butter increases lipid peroxidation but does not affect atherosclerotic, inflammatory, or diabetic risk markers in healthy young men. J. Nutr. 138:509514.

Ramsey, T. G., Evock-Clover, C. M., Steele, N. C. and Azain, M. J. 2001. Dietary conjugated linoleic acid alters fatty acid composition of pig skeletal muscle and fat. J. Anim. Sci. 9:2152-2161.

Riediger, N. D., Othman, R. A., Suh, M. and Moghadasian, M. H. 2009. A systemic review of the roles of $n-3$ fatty acids in health and disease. J. Am. Diet. Assoc. 109:668-679.

Roche, M., Noone, E., Sewter, C., Mc Bennett, S., Savage, D., Gibney, M., O'Rahilly, S. and Vidal-Puig, A. 2002. Isomerependent metabolic effects of conjugated linoleic acid. Diabetes 51:2037-2044.

Romans, J. R., Johnson, R. C., Wulf, D. M., Libal, G. W. and Costello, W. J. 1995a. Effects of ground flaxseed in swine diets on pig performance and on physical and sensory characteristics and omega-3 fatty acid content of pork: I. Dietary level of flaxseed. J. Anim. Sci. 73:1982-1986.

Romans, J. R., Johnson, R. C., Wulf, D. M., Libal, G. W. and Costello, W. J. 1995b. Effects of ground flaxseed in swine dietson pig performance and on physical and sensory characteristics and omega-3 fatty acid content of pork: II. Duration of $15 \%$ dietary flaxseed. J. Anim. Sci. 73:1987- 1999.

SAS Institute. 2003. SAS Stat User's Guide. Version 8. SAS Institute Inc., Cary, NC.

Selvaraj, R. and Cherian, G. 2004. Changes in delayed type hypersensitivity, egg antibody content and immune cell fatty acid composition of layer birds fed conjugated linoleic acid, n-6 or n-3 fatty acids. Can. J. Anim. Sci. 84:221-228.

Sioutis, S., Coates, A., Buckley, J., Murphy, T., Channon, H. and Howe, P. 2008. N-3 enrichment of pork with fish meal: Effects on production and consumer acceptability. Eur. J. Lipid Sci. Technol. 110:701-706.

Song, D. H., Kang, J. H., Lee, G. S., Jeung, E. B. and Yang, M. P. 2007. Upregulation of tumor necrosis factor-a expression by trans10-cis12 conjugated linoleic acid enhances phagocytosis of RAW macrophages via a peroxisome proliferator-activated receptor $\gamma$-dependent pathway. Cytokine. 37:227-235.

Stachowska E., Baśkiewicz-Masiuk, M., Dziedziejko, V., Adler, G., Bober, J., Machaliǹski, B. and Chlubek, D. 2007. Conjugated linoleic acids can change phagocytosis of human monocytes/ macrophages by reduction in Cox-2 expression. Lipids. 42: 707-716.

Sukhija, P. S. and Palmquist, D. L. 1988. Rapid method for determination of total fatty acid contents and composition of feedstuffs and feces. J. Agric. Food Chem. 36:1202-1206.

Takada, R. and Saitoh, M. 1998. Effect of dietary gamma-linolenic acid-enriched oil on backfat thickness and liver fatty acid degrading enzyme activity in growing pigs. Anim. Sci. Technol. 69:433-438.

Teye, G., Sheard, P., Whittington, F., Nute, G., Stewart, A. and Wood, J. 2006. Influence of dietary oils and protein level on pork quality. 1. Effects on muscle fatty acid composition, carcass, meat and eating quality. Meat Sci. 73:157-165.

Weaver, K., Ivester, P., Seeds, M., Case, D., Arm, J. and Chilton, F. 2009. Effect of dietary fatty acids on inflammatory gene expression in healthy humans J. Biol. Chem. 284:15400-15407.

White, H. M., Richert, B. T., Radcliffe, J. S., Schinckel, A. P., Burgess, J. R., Koser, S. L., Donkin, S. S. and Latour, M. 2009. Feeding conjugated linoleic acid partially recovers carcass quality in pigs fed dried corn distillers grains with soluble. J. Anim Sci. 87:157-166.

Wiegand, B. R., Parrish, F. C., Swan, J. E., Larsen, S. T. and Baas, T. J. 2001. Conjugated linoleic acid improves feed efficiency, decreases subcutaneous fat, and improves certain aspects of meat quality in stress-genotype pigs. J. Anim. Sci. 79:2187-2195. 
Witte, V. C., Krause, G. F. and Bailey, M. E. 1970. A new extraction method for determining 2-thiobarbituric acid values of pork and beef during storage. J. Food Sci. 35: 582585.

Xi, L., Brown, K., Woodworth, J., Shim, K., Johnson, B. and Odle, J.2008. Maternal dietary L carnitine supplementation influences fetal carnitine status and stimulates carnitine palmitoyl transferase and pyruvate dehydrogenase complex activities in swine. J. Nutr. 138:2356-2362.
Yaqoob, P. 2004. Fatty acids and the immune system: from basic science to clinical applications. Proc. Nutr. Soc. 63:89-104.

Yin, J. D., Shang, X. G., Li, D. F., Wang, F. L., Guan, Y. F. and Wang, Z. Y. 2008. Effects of dietary conjugated linoleic acid on the fatty acid profile and cholesterol content of egg yolks from different breeds of layers. Poult. Sci. 87:284-290.

(Received May 26, 2011; Revised Jun. 13, 2011; Accepted Jun. 16, 2011) 